\title{
Internacionalização de empresas como política de desenvolvimento: uma abordagem de diplomacia triangular*
}

\section{Ana Lucia Guedes**}

S U MÁRIO: 1. Introdução; 2. Desmistificando a globalização e resgatando a possibilidade de governança; 3. Globalização, investimentos diretos externos e governança no Brasil; 4. Modelo de diplomacia triangular; 5. Considerações finais e implicações políticas.

S UMMARY: 1. Introduction; 2. Demystifying globalization and recovering the possibility of governance; 3. Globalization, direct foreign investments and governance in Brazil; 4. Triangular diplomacy model; 5. Final remarks and political implications.

P ALA VRAS-CHAVE: política de desenvolvimento; internacionalização de em-presas; abordagem interdisciplinar.

KEY WORDS : development policy; internationalization of companies; interdisciplinary approach.

Este artigo desenvolve uma abordagem analítica da inserção do Brasil no contexto internacional contemporâneo, com base na literatura de economia política internacional e de negócios internacionais, que transcende as tradicionais avaliações de política internacional por contemplar relações que envolvem atores estatais e nãoestatais. Assim, o artigo sustenta que os desafios a serem enfrentados pelo Brasil resultam da complexidade do sistema internacional contemporâneo. O artigo apresenta um debate crítico acerca da globalização com objetivo de desmistificar esse fenômeno e resgatar a possibilidade de governança pelo âmbito público. Para ilustrar esse debate, é apresentada uma breve análise sobre os impactos da globaliza-

* Artigo recebido em nov. 2004 e aceito em set. 2005.

* Professora adjunta da Ebape/FGV. PhD em Relações Internacionais pela London School of Economics and Political Science, Inglaterra. Endereço: Praia de Botafogo, 190, sala 511 — Botafogo — CEP 22250-900, Rio de Janeiro, Brasil. E-mail: guedes@fgv.br. 
ção econômica, por meio de investimentos diretos externos, no Brasil. A abordagem analítica resultante enfatiza, com base no modelo de diplomacia triangular, que além das tradicionais negociações entre Estados, o Brasil precisa negociar com empresas estrangeiras e domésticas e, estas necessitam de alianças corporativas para enfrentar os desafios da economia mundial. Ao final, o artigo sugere que o governo brasileiro adote a internacionalização de empresas brasileiras como estratégia de desenvolvimento.

Company internationalization as a development policy: a triangular diplomacy approach

This article develops an analytical approach of the insertion of Brazil in the international context, grounded on the international political economy and international business literature, going beyond the traditional analysis in international politics as it contemplates the relationships between state and non-state actors. As such, the article stresses that the challenges faced by Brazil result from the complexity of the current international system. The article presents a critical debate regarding the globalization so as to demystify this phenomenon and stress the possibility of public governance. In order to ilustrate this debate, it develops a short analysis of the impacts of economic globalization through foreign direct investments in Brazil. The final analytical approach emphasizes, based on the triangular diplomacy model, that beyond the traditional negociation between states, Brazil has to negotiate with foreign and domestic companies and these need corporate alliances to face the challenges of the world economy. Finally, the article suggests that the Brazilian government adopt the internationalization of Brazilian companies as a development strategy.

\section{Introdução}

Este artigo está dividido em quatro seções, além desta introdução. A primeira apresenta um debate crítico sobre a globalização para desmistificar esse fenômeno e resgatar a possibilidade de governança no âmbito público. A segunda apresenta uma breve análise sobre os impactos da globalização econômica, por meio de investimentos diretos externos, no Brasil. A terceira apresenta inicialmente o modelo de diplomacia triangular para, a seguir, desenvolver uma análise das relações governogoverno, governo-empresa e empresa-empresa. Finalmente, são apresentadas algumas considerações finais e implicações políticas como resultado da abordagem analítica adotada. 
2. Desmistificando a globalização e resgatando a possibilidade de governança

Nas últimas décadas a crescente interdependência política e econômica intensificou a discussão sobre globalização. Esse fenômeno pode ser definido como um processo pelo qual as atividades estatais são desagregadas em favor de uma estrutura de relações entre diferentes atores que operam em um contexto que é global. Por conseguinte, é possível identificar algumas implicações do fenômeno para os Estados, das quais destacam-se duas: perda de soberania e perda de controle dos processos de tomada de decisões e os conseqüentes resultados (Held e McGrew, 2001).

Mais recentemente, após o colapso do chamado socialismo de Estado e da consolidação mundial do capitalismo, globalização tornou-se um conceito dominante tanto na academia como em diversos outros domínios da vida pública ou privada, e em todo e qualquer canto do mundo. Uma das características que merece destaque desse novo fenômeno é que todos dizem saber que globalização existe, mas ninguém sabe dizer exatamente do que se trata.

Alguns autores (Held e McGrew, 2001; Thompson, 2000) argumentam que não há de fato uma definição única e universalmente aceita para globalização. O problema mais sério por trás disso é que a globalização é marcada na literatura pela dominância de dois extremos teóricos que leva a posições extremas e não deixa muito espaço para o desenvolvimento de uma abordagem mais realista. Mais especificamente o debate na literatura, conforme Held e McGrew (2001), tem sido protagonizado por dois grupos extremos ou "faç̧ões": os que consideram a globalização um acontecimento histórico real e extremamente significativo, os chamados globalistas; e aqueles que concebem a globalização como construção ideológica ou mítica de valor explicativo marginal, os chamados céticos.

O modelo teórico defendido pelos céticos implica o reconhecimento da importância extrema das fronteiras nacionais - o qual deve remeter a perspectivas conceituais baseadas em imperialismo ou colonialismo - nos aspectos políticos, econômicos, sociais e legais correspondentes. Além disso, a proposta enfatiza questões políticas, mais especificamente o âmbito público e o governo, em vez de questões econômicas, o âmbito privado e as grandes empresas. O que é particularmente curioso é que essa proposta teórica vem ganhando força em diversas mídias, materializada na prática por manifestações de caráter nacionalista que se opõem à "globalização".

No outro extremo, os globalistas negam que globalização seja um constructo ideológico ou um sinônimo de imperialismo ou colonialismo. Para eles há evidências de mudanças estruturais reais na escala da organização social decorrente da expansão das empresas multinacionais e dos mercados de capitais, da difusão da cultura popular, e da crescente preocupação com a degradação ambiental do planeta. 
Aparentemente, eles não entendem a globalização como fenômeno exclusivamente econômico. Correspondentemente, eles defendem que pesquisadores e analistas devem adotar uma concepção multidimensional que contemple diversas redes de poder (econômica, política, ambiental, tecnológica, cultural etc.) e que desafie a perspectiva de universalização desses domínios.

No final das contas essa proposta cria o entendimento de que a dimensão econômica é mais importante do que as outras e de que a realidade vem assumindo uma configuração cada vez mais transnacional, a qual pressupõe ter importância cada vez mais reduzida para a dimensão nacional e para sua influência sobre o comportamento dos domínios econômico, social, político, legal etc. Mais especificamente, analistas de relações internacionais costumam classificar os autores influentes (como Ohmae, 1990) desta corrente de "hiperglobalistas” por eles acreditarem em um mundo sem fronteiras nacionais e na erosão do poder dos governos de “governar” a economia nacional.

Held e McGrew (2001) desafiam esse duelo na literatura monopolizado por globalistas e céticos e as correspondentes posições extremas a favor do Estado ou das corporações. Eles argumentam que a conceituação de globalização deve contemplar três aspectos fundamentais: material, espaço-temporal e cognitivo. O primeiro é representado pelos fluxos de comércio, capital e pessoas, os quais são facilitados pelas infra-estruturas de natureza física (transportes e informática), normativa (regras do comércio internacional) e simbólica (a língua inglesa como língua universal). O segundo decorre da mudança no alcance espacial da ação e da organização social entre os níveis local e global. O terceiro se manifesta pela conscientização da relação causal entre acontecimentos distantes e questões locais (e vice-versa), bem como em mudanças correspondentes em termos de noções de tempo e espaço.

Essa argumentação, segundo os autores, pressupõe a existência de globalização. Entretanto a mesma não pressupõe a inevitável harmonia de interesses, universalização de valores e, enfim, a convergência de culturas e civilizações. Para eles, globalização é um processo complexo e socio-histórico que carrega muitas características e práticas de natureza política. Globalização, segundo essa proposta, gera processos dinâmicos de animosidade e conflito.

Apesar de ausência de consenso quanto ao conceito de globalização, todos questionam a existência de alguma forma de governança global capaz de gerenciála. Outras áreas de estudo em globalização vêm sendo desprezadas por pesquisadores em administração e isso vem contribuindo para impedir o reconhecimento de aspectos de governança. Entre as áreas de estudo, três merecem destaque: economia política internacional, focada na economia global (Strange, 1994); estudos culturais, focados na cultura global (Featherstone, 1990); sociologia global, focada em classes transnacionais (Sklair, 1995). 
Apesar de essas três áreas reconhecerem que o conceito de globalização ainda é impreciso, seus autores argumentam que a governança é o ponto que não pode deixar de ser problematizado. Mais especificamente, a questão central para esses pesquisadores é: existe alguma forma de governança global para lidar com esses processos (Hirst e Thompson, 1998)? Nessa linha de raciocínio, Thompson (2000) sustenta que a estrutura (o sistema econômico internacional e seus agentes, as empresas transnacionais) não domina a agência (das economias nacionais e seus governos) na mesma medida em que isso é declarado pela abordagem globalista.

Contra a noção globalista, de empresas transnacionais (ETNs) como símbolos da globalização, alguns teóricos (Ruigrok e van Tulder, 1995; Hirst e Thompson, 1998) afirmam que nenhuma dessas corporações pode ser considerada como "global”, footloose ou "sem fronteiras". Dicken (1998:193) relata a evolução da internacionalização das atividades econômicas no pós-guerra com as mudanças na organização da produção industrial, aumento do comércio internacional e do número de subsidiárias de ETNs, mas afirma que existe pouca, se alguma, corporação verdadeiramente "global". Gilpin $(2000,2001)$ afirma que as multinacionais existem atualmente como atores transnacionais porque isso é consistente com o interesse político da potência hegemônica no pós-guerra. Assim, os fatores econômicos e tecnológicos foram secundários em formatar os modos de produção porque eles se tornam relevantes somente quando os EUA criam a necessária estrutura política para a internacionalização.

Por outro lado, não obstante o discurso predominante de liberalização econômica ao longo da década de 1990, os países desenvolvidos continuam fechados em termos de interdependência e de integração de investimentos. Tendo em vista a assimetria histórica entre países desenvolvidos e países em desenvolvimento isso significa que a dimensão política internacional continua sendo mais "governada” pelos primeiros do que pelos segundos.

Em resumo, é necessário desmistificar o argumento de que a globalização econômica é o principal processo organizador da sociedade contemporânea, com ênfase nas forças do livre mercado e da competição (Forjaz, 2000). Cabe também desafiar os formuladores de políticas que subestimam o que pode ser feito para gerenciar a economia internacional e as economias nacionais. Em outras palavras, governança local continua sendo um espaço para ser disputado por governos ou Estados mesmo que isso implique a modificação de políticas nacionais e regionais (Wilson, 2000). 
3. Globalização, investimentos diretos externos e governança no Brasil

A definição de governança tem gerado amplo debate sem que qualquer consenso seja obtido. O Banco Mundial define governança como o exercício de poder político no gerenciamento dos assuntos do país. Mais detalhadamente, o termo enfatiza o gerenciamento dos recursos econômicos e sociais do país com o propósito de desenvolvimento (World Bank, 1992:3). No entanto, essa definição gerou inúmeras críticas. Alguns argumentam que ela é apenas uma tentativa de impor o modelo democrático-liberal ocidental aos países em desenvolvimento; outros argumentam que ela tenta disfarçar uma visão neoliberal de um setor público mais enxuto e eficiente além de consistente com as necessidades do desenvolvimento capitalista.

No Brasil, o âmbito da governança vem sendo sistematicamente negligenciado sob as premissas de uma visão particular de globalização que foi propagada e implementada ao longo da última década. Até o início dos anos 1990, o grau de abertura da economia brasileira era um dos menores entre os países ocidentais. Empresas estrangeiras e domésticas se beneficiaram das medidas protecionistas do mercado brasileiro até que políticas de liberalização comercial foram abruptamente adotadas (Furtado, 1999).

Em paralelo, o significativo crescimento do processo de fusões e aquisições em âmbito mundial teve reflexos no Brasil (Gonçalves, 1999). O ingresso de investimento direto externo (IDE) estava fortemente associado ao processo de privatizações e ao fenômeno de fusões e aquisições. Assim, o Brasil se tornou um grande receptor de IDE (ver tabela) assumindo a posição de destaque entre os países emergentes.

\begin{tabular}{|lccccccc|}
\hline \multicolumn{7}{|c|}{ Fluxos de IDE - Brasil (US\$ milhões) } \\
\hline 1997 & 1998 & 1999 & 2000 & 2001 & 2002 & $2003^{*}$ \\
\hline Brasil & $18.992,9$ & $28.855,7$ & $28.578,4$ & $32.779,2$ & $22.457,4$ & $16.566,0$ & $9.100,0$ \\
\hline $\begin{array}{l}\text { Fonte: Unctad, 2002, 2003. } \\
\text { * Estimativa da Unctad. }\end{array}$ & & & & & & \\
\hline
\end{tabular}

Para alguns teóricos, a elevação dos fluxos de IDE e das atividades das ETNs tem mudado a natureza dos Estados e os seus padrões de conduta. Por exemplo, Clark (1997:184) afirma que os Estados passaram a considerar as corporações não como rivais, mas como aliados bem-vindos na busca de vantagens competitivas em um mercado internacional precário. 
Cabe destacar, entre as transformações decorrentes do volume de investimentos no período de 1990-98 na economia brasileira, as alterações significativas na estrutura de controle acionário das 100 maiores empresas não-financeiras. Em 1990, a participação de propriedade estrangeira e nacional era equivalente (27 empresas cada). Mas houve um avanço significativo da presença de empresas estrangeiras (passaram a ser 34 empresas) que tornaram-se responsáveis por $40 \%$ do total da receita das 100 maiores da economia brasileira. Essa elevada participação de empresas estrangeiras no Brasil pode ser comparada, segundo Siffert e Silva (1999:404-405) com a estrutura de internacionalização das economias da Bélgica, Espanha e Áustria.

Em resumo, as implicações das profundas transformações, em termos políticos, econômicos, sociais e ambientais, ainda estão sendo investigadas (Gonçalves, 1999; Arbix, 2000), mas podemos afirmar que a abertura da economia não elevou a participação do Brasil no comércio internacional. Mais especificamente, tal postura resultou em uma redução — de 1,4\% na metade dos anos 1980 para 0,9\% em 1999 — da participação percentual do país no comércio mundial. A inserção internacional do Brasil permanece refém das estratégias mercadológicas de subsidiárias de empresas transnacionais; da exportação de produtos primários sujeitos ao protecionismo dos EUA e da União Européia (UE) e da deficiente capacidade exportadora das empresas brasileiras (sobre esse último aspecto ver Rocha, 2002 e Pinheiro et al., 2002).

Mais especificamente, Laplane e Sarti (1999) concluem que apesar do incremento do fluxo de IDE ao longo da década de 1990, suas características limitam sua contribuição para o crescimento do país. A concentração da produção em bens de consumo e de intermediários para o mercado interno, associada à importação de equipamentos, matérias-primas e componentes indica que o IDE não altera significativamente a pauta exportadora.

Nonnenberg (2003:63-64) conclui que mais da metade dos fluxos de IDE entre 1996 e 2000 resultou das políticas de privatização e desregulamentação, principalmente o setor de serviços. As ETNs no setor industrial somente consolidaram posições em setores amplamente desenvolvidos. O autor destaca ainda o papel das ETNs no recente processo de reestruturação industrial - aumento das importações, a desverticalização da produção e o downsizing.

O discurso, defendido por corporações transnacionais, tecnocratas de agências multilaterais e políticos, de que os novos modos de governança, baseados na interdependência e na dissolução de fronteiras, são mais efetivos do que outros modos “tradicionais” para a promoção de desenvolvimento socioeconômico local, por permitirem a integração mais equilibrada do "mercado" e do "Estado”, deveria ser criticamente revisto no Brasil.

Também deve ser desafiado o senso comum de que "parcerias” envolvendo agentes públicos e privados podem trazer desenvolvimento industrial, regional e na- 
cional sustentável para todo e qualquer país (Sternberg, 2000). Essas “parcerias” são tidas como mais efetivas do que as políticas industriais controladas pelos Estados (Santos, 2002) por não serem baseadas em comando e autoridade "mas sim em negociação e barganha”.

Como já demonstrado em estudos focados na guerra fiscal no Brasil (Arbix, 2000), é esperado que pesquisas futuras venham a demonstrar que práticas de "governança” correspondentes têm envolvido estruturas e negociações assimétricas entre Estados ou governos e corporações transnacionais e que as mesmas afetam e são afetadas por questões e práticas do nível "gerencial”, nos âmbitos da gerência na empresa privada e da administração pública.

Os formuladores de políticas devem reconhecer que atores transnacionais - incluindo empresas e diversas instituições — vêm ocupando o vazio deixado pelo Estado, ou pelo governo, e que muitas delas vêm exercendo governança de forma contraditória (Sklair, 2001) e mesmo injusta (Franceschet, 2002) nos mais diversos países — principalmente nos menos desenvolvidos. Cabe, então, ao Estado retomar seu papel de articulador das interfaces público-privada e interna-externa, mesmo em um contexto internacional caracterizado pela multiplicidade de temas e atores e pela complexidade de visões e interesses conflitantes (Guimarães, 1999:144).

Na próxima seção, este artigo destaca, com base na estrutura de análise do modelo de diplomacia triangular, alguns dos principais desafios a serem enfrentados pelo governo com o propósito de melhorar a inserção internacional do Brasil.

\section{Modelo de diplomacia triangular}

O modelo de diplomacia triangular é o resultado de uma rara colaboração interdisciplinar, entre acadêmicos de economia política internacional e negócios internacionais, focado nas relações entre atores estatais e não-estatais em países em desenvolvimento. Com base na crescente interdependência observada nas décadas de 1970 e 1980, Stopford e Strange (1991) argumentam que os governos passaram a reconhecer a dependência de recursos controlados por ETNs. Mais especificamente, eles ressaltam que mudanças estruturais nas dimensões tecnológica, financeira e política "obrigaram” os governos a cooperar com essas corporações. Argumento similar é desenvolvido, posteriormente em Dicken (1998) e Strange (1994, 1996).

Com base nesses argumentos os autores investigaram processos de negociação e de barganha, entre governo e empresa, em projetos de investimento em três países em desenvolvimento - Brasil, Malásia e Quênia. Entre as contribuições do estudo, e particularmente para sustentar o argumento de que o âmbito da governança pública deve ser problematizado, destacam-se as duas novas dimensões da diplomacia. Ou seja, além das tradicionais negociações entre Estados, os autores indicam que eles precisam negociar com as ETNs. Por seu lado, essas empresas for- 
mam alianças corporativas para lidar com o mercado global. A interação simultânea das três dimensões do modelo de diplomacia triangular (ver figura) proposto pelos autores exige novas qualificações dos gerentes e burocratas em termos de governança.

Os autores concluem que governos em geral perderam poder de barganha para as ETNs, principalmente em países em desenvolvimento. Os Estados ainda controlam o acesso ao território e a mão-de-obra naquele território, mas empresas controlam capital e tecnologia. A maior importância do capital e da tecnologia no sistema capitalista contemporâneo elevou consideravelmente o poder de barganha das ETNs. Conseqüentemente, os autores prescrevem que governos e empresas devem aprender a lidar mais efetivamente com as complexidades correspondentes.

Este artigo sustenta que os desafios a serem enfrentados pelo Brasil resultam da complexidade do sistema internacional contemporâneo. Dessa forma, o artigo enfatiza que, além das tradicionais negociações entre Estados, o Brasil precisa negociar com empresas estrangeiras e domésticas e elas necessitam de alianças corporativas para enfrentar os desafios do mercado global. Serão destacados, a seguir, aspectos específicos de cada um dos âmbitos do modelo de diplomacia triangular.

Modelo de diplomacia triangular

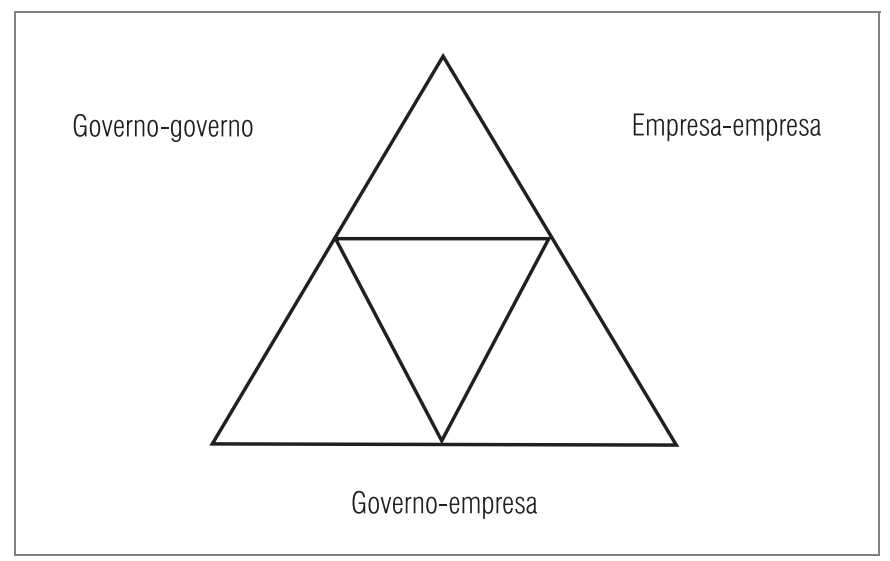

Fonte: Stopford e Strange, 1991:22. 


\section{Âmbito das relações governo-governo}

No âmbito das tradicionais relações governo-governo, a diplomacia brasileira tem recentemente concentrado seus esforços em três conjuntos de países (ver Almeida, 1999, para uma perspectiva mais ampla do estudo das relações internacionais do Brasil). O primeiro conjunto, e talvez mais relevante devido aos eventuais problemas transfronteiriços e a proximidade hemisférica da potência hegemônica, resulta do aprofundamento das relações com os países da América Latina, já que isso concretiza o histórico "potencial” de liderança na região por meio da integração (Pereira, 2001) e não da imposição das visões e interesses brasileiros (Fonseca Jr., 1998).

O segundo resulta do estreitamento das relações com países emergentes (ou potências regionais, ver Rebelo, Fernandes e Cardim, 2003) de outros continentes com posição relativa no cenário internacional próxima da brasileira, tais como as recentes tentativas de vínculos com a África do Sul, Índia, China e Rússia. A probabilidade de convergência de visões e interesses estratégicos é muito mais elevada entre esses países do que, por exemplo, qualquer tentativa de estabelecimento de vínculos com os países desenvolvidos da Europa. Seguindo a lógica de que a formação de alianças não é um jogo de soma zero, esses países poderiam obter resultados positivos em conjunto principalmente nas negociações multilaterais. É relevante mencionar que interessa particularmente a esses países uma configuração de poder multipolar no sistema internacional e o "enfrentamento" das estruturas hegemônicas que impedem o desenvolvimento de suas potencialidades (Guimarães, 1999).

O terceiro refere-se à comunidade de países de língua portuguesa (Rebelo, Fernandes e Cardim, 2003). Em eventos recentes, como o ocorrido no Timor Leste, outras potências regionais acabaram liderando programas de ajuda humanitária e de reconstrução. Existe a expectativa de posicionamento mais ativo do governo brasileiro diante das eventuais demandas de organismos internacionais visto que tais atividades podem beneficiar empresas brasileiras no exterior. Isso pode ser ilustrado pelo envio, em 2004, de tropas brasileiras para o Haiti.

Ainda no âmbito das relações governo-governo, cabe uma breve consideração sobre as relações do Brasil com a Europa (Rebelo, Fernandes e Cardim, 2003). A posição relativa dos países europeus nas estruturas de poder (Strange, 1994) resulta em certa ambigüidade com relação aos países periféricos. Isso se deve em parte às articulações e aos alinhamentos com os EUA, principalmente em termos militares, no pós-guerra. As eventuais oportunidades de cooperação com países como o Brasil decorrem dos conflitos entre os países europeus e os EUA nas demais dimensões das relações internacionais contemporâneas. Mais especificamente, dos conflitos de visões e interesses nas questões ambientais e culturais, e mais recentemente quanto às decisões unilaterais na área de segurança (Buzan, 2002). 
No entanto, os formuladores e executores da política externa consideram normalmente como primordiais as relações Brasil-EUA. Ao Brasil cabe a difícil tarefa histórica de manter uma posição intermediária entre a submissão e o confronto. No entanto, as ambigüidades e, mais recentemente, o unilateralismo explícito da política externa norte-americana dificultam o posicionamento do Brasil com relação à potência hegemônica. Assim, resta ao Brasil explorar seu poder de barganha em outros tópicos da agenda internacional, independentemente dessa ter sido ou não definida de acordo com as visões e interesses paroquiais dos EUA (Dupas, 2003).

De um lado temos tópicos que podem resultar em situações conflitantes, como a liderança brasileira na articulação de iniciativas em defesa dos interesses da América do Sul; os exercícios militares norte-americanos em regiões de fronteiras com o Brasil; as operações contra o narcotráfico e o terrorismo; as questões ambientais envolvendo a Amazônia e, finalmente, a visão de que as Forças Armadas dos países sulamericanos devem ser reduzidas ao papel de polícia interna (Guimarães, 1999:145).

Por outro lado, o Brasil tem historicamente se beneficiado das articulações com terceiros países nos fóruns multilaterais (Rebelo, Fernandes e Cardim, 2003). Isso se deve basicamente à posição do país, em termos geopolíticos, na América Latina e a reconhecida atuação da diplomacia brasileira. Esses ativos não têm sido negligenciados na busca dos interesses estratégicos brasileiros na esfera internacional. Em outras palavras, apesar de historicamente acanhada, a liderança brasileira na América Latina deve ser usada como barganha nas relações Brasil-EUA (Jaguaribe, 1996). Dessa forma, as iniciativas que produzam vínculos tanto em termos de comércio quanto de investimentos brasileiros e desenvolvimento de infra-estrutura conjunta têm sido privilegiadas, como, por exemplo, a construção do gasoduto Brasil-Bolívia.

A participação do Brasil nos fóruns internacionais multilaterais é, estrategicamente, relevante apesar dos questionamentos quanto à legitimidade deles nas questões contrárias aos interesses dos EUA. Por exemplo, a estratégia brasileira de obter apoio internacional para sua candidatura como membro do Conselho de Segurança é importante em decorrência da concentração de poder político e militar que resulta das necessárias reformas no âmbito da Organização das Nações Unidas (ONU) e da sistemática imposição de acordos desiguais para controle de armamentos (Fonseca Jr., 1998). Seria relevante mencionar ainda que o discurso oficial brasileiro de priorizar, na agenda internacional, questões de pobreza e desenvolvimento está em sintonia com o discurso do secretário-geral da ONU. A iniciativa do Fórum Social Mundial tem substanciado tais afirmações além de dar projeção internacional ao Brasil (Gómez, 2002).

Adicionalmente, o fortalecimento do Mercosul e as negociações com o objetivo de viabilizar a formação de uma zona de livre-comércio com a União Européia são relevantes instrumentos de barganha em face de um outro aspecto das relações Brasil-EUA: as negociações da Área de Livre Comércio das Américas (Alca). As 
negociações (com prazo de conclusão previsto para 2005) no âmbito da Alca têm levado em consideração a sua complexidade em termos de assimetria dos estágios de desenvolvimento dos países negociadores e a elevada proporção de comércio intrafirmas (Reza, 2002).

Como um dos principais parceiros comerciais do Brasil, o foco das negociações está na potencialidade de redução das medidas protecionistas norte-americanas que afetam diretamente as exportações brasileiras (Pereira, 2001). Isso significa também que o Brasil continue explorando os mecanismos de solução de controvérsias no âmbito da Organização Mundial do Comércio (OMC) como instrumento de barganha nos momentos mais críticos. A regulamentação do comércio internacional no âmbito da OMC requer a estruturação e capacitação de instâncias domésticas para agilizar a resolução de contenciosos comerciais (Lafer, 1998:24; Carvalho, 2003).

A liderança brasileira no atual processo de ampliação do Mercosul (Hurrell, 1995) e nas negociações simultâneas com as da Alca, para a criação de zona de livrecomércio com a UE, eleva o poder de barganha do país no cenário internacional. Porém, a inserção dos países sul-americanos na economia mundial depende também de ações conjuntas, em termos de infra-estrutura de transporte, energia e telecomunicações, que podem advir das tentativas de integração regional (Pereira, 2001).

A participação brasileira em outros regimes internacionais, como o de não-proliferação de armas nucleares, de mudanças climáticas, de florestas tropicais e de direitos humanos, fortalece o poder de barganha do país desde que articulado em conjunto com outros países emergentes. Mais especificamente na área ambiental, fica evidente o poder de barganha favorável ao Brasil. Dessa forma, o país possui expressiva margem de manobra, como resultado da biodiversidade, da base energética renovável e da ausência de armas e usinas nucleares, para refutar qualquer imposição de política internacional que penalize o uso sustentável dos recursos naturais bem como que vincule desenvolvimento a metas rígidas de conservação e preservação ambiental (Viola e Olivieri, 1997).

Por último, mas não menos importante, a área temática de direitos humanos requer atenção especial devido às diferenças entre suas dimensões interna e externa. Não resta dúvidas quanto aos necessários avanços internos em termos de direitos políticos, econômicos e sociais. Mas isso não implica que o país se sujeite a manipulações externas quando o tema é usado como instrumento de poder no sistema internacional (Santos, 2001). 


\section{Âmbito das relações governo-empresa}

No âmbito das relações governo-empresa, o modelo de diplomacia triangular (Stopford e Strange, 1991) exige uma diplomacia comercial ativa que integre governo e setor privado e que esteja simultaneamente engajada tanto nas negociações multilaterais, no âmbito da OMC, quanto no fortalecimento de zonas de livre-comércio. A complexidade da atuação em várias frentes parece indicar a necessidade de criação de grupos de trabalho, sob coordenação dos representantes dos respectivos ministérios, com representantes das partes diretamente interessadas (ou afetadas) nas áreas temáticas da pauta de negociações brasileira. Seria também, particularmente relevante, a participação de representantes dos grupos de interesse com o propósito de disponibilizar aos demais seus conhecimentos dos temas (Carvalho, 2003).

Estudos recentes, realizados por pesquisadores da Universidade de Campinas, ${ }^{1}$ indicam dois grupos de setores como os mais competitivos para enfrentar o choque de liberalização que pode resultar das negociações da Alca. No primeiro grupo, encontram-se os setores: siderúrgico, café, couro, calçados, celulose e papel e sucos. No segundo, os setores de cosméticos, madeira, móveis e revestimentos cerâmicos. Entre os setores menos competitivos, segundo tais estudos, encontram-se os de construção naval, plásticos, têxteis e confecções, petroquímica e bens de capital. Há ainda a indicação de um quarto grupo, muito relevante em face da potencialidade de exportação de produtos industrializados, cuja competitividade depende de decisões tomadas por empresas transnacionais. Fazem parte desse grupo os setores de veículos, equipamentos de comunicação, eletrônicos de consumo, informática e farmacêutico.

O fato de que a tão necessária expansão das exportações brasileiras depende, em alguns setores específicos, de decisões tomadas por empresas transnacionais implica vulnerabilidade externa para o país. Assim, a busca de crescimento sustentável e de redução da vulnerabilidade do governo brasileiro diante dos investimentos externos depende de ações conjuntas, o que inclui incentivar a internacionalização de empresas brasileiras (além das tradicionais políticas de promoção de exportação), e o acesso a capital e a tecnologia de ponta (recursos controlados em sua maioria por empresas transnacionais, ver Moran, 1998).

Segundo dados da Unctad (2002) apenas Petrobras, Gerdau, Vale do Rio Doce e Varig estão entre as 50 maiores empresas transnacionais de países em desenvolvimento, com base no volume de ativos no exterior em 2000 (ver quadro). A falta de projeção do Brasil entre as maiores de países em desenvolvimento, apesar

\footnotetext{
${ }^{1}$ Jornal da Unicamp, v. 17, n. 197, 4 a 10 nov. 2002, e Folha de S. Paulo, 1 jun. 2003.
} 
desse levantamento não considerar outras empresas brasileiras com operações no exterior, demonstra mais uma vulnerabilidade do país frente aos demais.

\begin{tabular}{|lc|}
\hline \multicolumn{2}{|c|}{ Maiores empresas transnacionais brasileiras } \\
\hline Empresa & Setor \\
\hline Petróleo Brasileiro — Petrobras & Petróleo \\
Grupo Gerdau & Metalúrgico \\
Companhia Vale do Rio Doce — CVRD & Mineração \\
Viação Aérea Rio-Grandense — Varig & Transporte e carga \\
Empresa Brasileira de Aeronáutica — Embraer & Aeronaves \\
Teka — Tecelagem Kuehnrich & Tecelagem \\
Banco do Brasil & Financeiro \\
Banco Bradesco & Financeiro \\
Banco Itaú & Financeiro \\
\hline Fonte: Unctad, 2003. & \\
Obs.: Setor financeiro com base no volume de ativos de 2001/02, nos demais com base no volume de vendas \\
de 2000.
\end{tabular}

Nesse caso específico, de promoção de internacionalização, a Unctad (2000:13) indica políticas promocionais que intensificam a habilidade das empresas para investir no exterior:

t assistência técnica e informação para a comunidade de negócios, principalmente para pequenas empresas, com relação às oportunidades de investimento direto no exterior (como nos casos da Coréia, Cingapura e Tailândia);

t apoio financeiro direto e/ou incentivos fiscais para investimentos no exterior, por meio de medidas que são freqüentemente adaptadas dos programas de promoção de desenvolvimento industrial, de exportação e de atração de IDE (como nos casos da Coréia, Índia, Cingapura, Tailândia, Malásia e Taiwan);

t fazer seguros para os investimentos contra riscos não-comerciais para as empresas domésticas investindo no exterior. 
Os estudos realizados pela Unctad (2000:13), na metade da década de 1990, enfatizam que os países em desenvolvimento que obtiveram sucesso com estratégia orientada para as exportações adotaram uma postura "liberal” quanto à permissão de que as empresas invistam no exterior. Um primeiro motivador é facilitar o acesso aos mercados, o que implica unidades produtivas em países anfitriões para expandir a penetração no mercado e evitar atuais e futuras barreiras comerciais. Mais recentemente, um motivador adicional é o acesso a tecnologias que podem futuramente auxiliar na reestruturação da economia. Uma relevante questão continua, no entanto, a gerar certa polêmica: se países em desenvolvimento devem buscar inicialmente eficiência doméstica e promoção das exportações antes de incentivarem investimentos diretos no exterior.

Recentemente, o ministro do Desenvolvimento admitiu que ainda falta ao governo um plano para incentivar a internacionalização das empresas brasileiras. ${ }^{2}$ Segundo o ministro, as crescentes exportações dariam origem a um movimento natural de internacionalização. O que, ao menos superficialmente, responde o questionamento do parágrafo anterior. Algumas semanas depois, uma decisão do presidente da República ilustra a dificuldade do atual governo para lidar com a questão diante dos interesses externos no país: o governo decide revogar a diferença das taxas de juros para financiamentos concedidos pelo Banco de Desenvolvimento Econômico e Social (BNDES) terminando, assim, com o diferencial nos juros cobrados para empresas de capital nacional e estrangeiro. ${ }^{3}$

Outro aspecto relevante se refere às dificuldades enfrentadas pelas empresas brasileiras quanto ao processo de internacionalização. Rocha (2002) menciona algumas delas, como, por exemplo, que as poucas empresas internacionalizadas não dispõem de práticas estruturadas para a gestão de recursos humanos internacionais. A ausência de incentivos governamentais e o despreparo do empresariado brasileiro o que não isenta a academia da sua parcela de responsabilidade na formação dos líderes governamentais, empresariais, funcionários públicos e gerentes — estão refletidos no levantamento das maiores ETNs de países em desenvolvimento.

Cabe enfatizar que formuladores de políticas devem considerar essas lacunas apontadas acima em futuras metas de desenvolvimento. Pois, ao levá-las em consideração, o Estado retoma o seu papel de articulador das interfaces dos âmbitos público-privado, interno-externo e político-econômico.

No caso específico das relações governo-ETNs, estudo recente da Unctad (2004) indica que 400 das 500 maiores empresas listadas na revista Fortune operam no Brasil. No entanto, o estudo enfatiza o foco dos investimentos no mercado interno, e que os IDEs não estão contribuindo para a redução das disparidades econômi-

\footnotetext{
2 O Globo, 6 mar. 2004, Caderno Economia, p. 31.

${ }^{3}$ Gazeta Mercantil, 14 abr. 2004, p. A1.
} 
cas regionais e são responsáveis por apenas 2,1\% do total dos empregos da economia brasileira. $\mathrm{O}$ estudo identifica também como dificuldades a serem superadas pelo governo brasileiro para a atração de IDE, a ausência de um quadro normativo (nos âmbitos tributário e de propriedade intelectual) e os custos de infra-estrutura. Ao final, o estudo recomenda a criação de uma agência federal de promoção de investimentos e de agências estaduais na implementação de mecanismos de acompanhamento na fase posterior ao investimento.

\section{Âmbito das relações empresa-empresa}

No âmbito das relações empresa-empresa, o modelo de diplomacia triangular (Stopford e Strange, 1991) sugere medidas mais audaciosas para forçar alianças, parcerias e, principalmente, no caso de países em desenvolvimento, a transferência de tecnologias gerenciais e operacionais das grandes empresas transnacionais para as suas respectivas redes de fornecedores, prestadores de serviços e consumidores industriais.

No entanto, os estudos empíricos sobre internacionalização de empresas transnacionais indicam, quando focados em operações no Brasil, que as subsidiárias apenas executam estratégias de mercado das matrizes (Oliveira Jr. e Borini, 2003). Adicionalmente, o processo de integração no âmbito do Mercosul demonstra que essas empresas promoveram mudanças estruturais buscando eficiência de produção e comercialização de produtos (Chudnovsky, 1999).

Essas mudanças resultaram em substituição de insumos e componentes domésticos por importados, fechamento de plantas ou linhas de produção, reestruturações organizacionais e terceirizações com efeitos negativos no emprego. É importante, também, mencionar que o acesso ao mercado interno do Brasil tem sido a principal motivação para os fluxos de IDE (Furtado, 1999; Chudnovsky, 1999; Unctad, 2004) sem que isso tenha criado capacidade produtiva ou elevação das exportações.

Assim, parece haver margem para negociações no âmbito governo-empresa que produzam resultados concretos no âmbito empresa-empresa, principalmente no que refere aos supostos benefícios dos IDEs, tais como qualificação e capacitação de fornecedores e distribuidores nacionais e transferência de tecnologias operacionais e gerenciais para empresas domésticas. Em outras palavras, os benefícios dos IDEs somente serão obtidos com a intermediação dos governos já que eles, principalmente em países em desenvolvimento, perderam poder de barganha para as ETNs que controlam o acesso ao capital e à tecnologia (Stopford e Strange, 1991). 
Com base nos estudos acima, o governo brasileiro não parece ter obtido resultados que viabilizem crescimento sustentável. No entanto, esses resultados não implicam que não existam exemplos de alianças estratégicas entre ETNs e empresas domésticas. Rodrigues (1999) relata resultados de estudos focados em joint ventures, associações entre empresas brasileiras e estrangeiras, como oportunidade para obtenção e manutenção de competitividade. Entre os setores mencionados encontram-se os de papel e celulose, eletroeletrônica, mineração e telecomunicações.

É possível identificar, novamente, que o governo pode exercer a sua capacidade de formulação de política levando em consideração o que lhe resta de poder de barganha ante as ETNs, isoladamente, as empresas domésticas, isoladamente ou em grupos, ou ainda, a ambas, estrangeiras e domésticas, quando aliadas em associações empresariais.

\section{Considerações finais e implicações políticas}

Este artigo desenvolveu uma abordagem analítica do contexto internacional contemporâneo, com base na literatura de economia política internacional e de negócios internacionais, e identificou tópicos da agenda internacional que dificultam a inserção do Brasil. A análise da inserção do Brasil no contexto internacional contemporâneo, desenvolvida neste artigo com base no modelo de diplomacia triangular, implica uma investigação complexa cujo foco transcende as tradicionais avaliações das ações e interações dos Estados dentro de um sistema internacional anárquico.

Isso decorre basicamente do fato de que as relações internacionais são caracterizadas por uma multiplicidade de temas e atores que podem, sob o risco de demasiada simplificação, ser agrupados nas seguintes dimensões: militar, econômica, sociocultural e ambiental. Cada uma delas representa distintas configurações e relações de poder entre os Estados, entre Estados e atores não-estatais e, ainda, entre os atores não-estatais.

Cabe destacar a relevância da integração dos Estados ao sistema internacional porque certas metas de desenvolvimento somente podem ser alcançadas quando Estados estão mais inter-relacionados com outros Estados e com atores não-estatais. Conseqüentemente, como o sistema é constituído de múltiplos atores, a característica que os define é a autonomia em vez da soberania e a posição relativa dos atores depende da área temática.

Ao analisar os três âmbitos do modelo de diplomacia triangular, o artigo identifica uma lacuna, tanto na análise de Stopford e Strange (1991) quanto no âmbito de políticas públicas, nas relações governo-empresa no Brasil. Isso decorre, especifica- 
mente, da excessiva ênfase na atração de investimentos externos ao longo da última década em detrimento de políticas que promovam a internacionalização de empresas brasileiras. Cabe notar que as relações entre o governo e as ETNs evoluíram muito nas últimas décadas, diante da desconfiança mútua e do controle do passado sem que medidas equivalentes de incentivo à internacionalização de empresas brasileiras tenham sido adotadas.

Este artigo enfatiza que os formuladores de políticas públicas não devem subestimar o que ainda pode ser feito para gerenciar a economia internacional e as economias nacionais. $\mathrm{O}$ âmbito da governança permanece como um espaço a ser disputado por Estados mesmo que isso implique a modificação de políticas. O Estado retoma então seu papel de articulador das interfaces público-privada e interna-externa mesmo que em um contexto internacional caracterizado pela multiplicidade e complexidade. Em particular, cabe destacar a potencialidade de formulação e implementação de política pública que adote a internacionalização de empresas como estratégia de desenvolvimento.

\section{Referências bibliográficas}

ALBUQUERQUE, J. A. G.; OLIVEIRA, H. A. (Orgs.). Relações internacionais e sua construção jurídica. v. 1. São Paulo: FTD, 1998.

ALMEIDA, P. R. de. A diplomacia do liberalismo econômico. In: ALBUQUERQUE, J. A. G. (Org.). Sessenta anos de política externa brasileira (1930-1990). Crescimento, modernização e política externa. v. 1. São Paulo: Cultura Editores Associados, 1996.

O estudo das relações internacionais do Brasil. São Paulo: Unimarco, 1999.

ARBIX, G. Guerra fiscal e competição intermunicipal por novos investimentos no setor automotivo. Dados — Revista de Ciências Sociais, Rio de Janeiro, v. 43, n. 1, p. 5-43, 2000.

BRIGAGÃO, C. (Org.). Estratégias de negociações internacionais. Rio de Janeiro: Aeroplano, 2001.

BUZAN, B. As implicações do 11 de setembro para o estudo das relações internacionais. Contexto Internacional, Rio de Janeiro, v. 24, n. 2, p. 233-265, jul./dez. 2002.

CARVALHO, M. I. V. Estruturas domésticas e grupos de interesse: a formação da posição brasileira para Seattle. Contexto Internacional, Rio de Janeiro, v. 25, n. 2, jul./dez. 2003. 
CHUDNOVSKY, D. (Org.). Investimentos externos no Mercosul. Campinas: Papirus, Instituto de Economia da Unicamp, 1999.

CLARK, I. Globalization and fragmentation. Oxford: Oxford University Press, 1997.

DICKEN, P. Global shift - transforming the world economy. 3. ed. London: Paul Chapman, 1998.

DUPAS, G. Hegemonia norte-americana, governabilidade global e impasses nos grandes países da periferia. Contexto Internacional, Rio de Janeiro, v. 25, n. 2, jul./dez. 2003.

FEATHERSTONE, M. Cultura global. Petrópolis: Vozes, 1990.

FONSECA JR., G. A legitimidade e outras questões internacionais. São Paulo: Paz e Terra, 1998.

FORJAZ, M. C. S. Globalização e crise do Estado nacional. Revista de Administração de Empresas, São Paulo, v. 40, n. 2, p. 38-50, abr./jun. 2000.

FRANCESCHET, A. Justice and international organization: two models of global governance. Global Governance, v. 8, p. 19-34, 2002.

FURTADO, C. O capitalismo global. São Paulo: Paz e Terra, 1999.

GILPIN, R. The challenge of global capitalism. Princeton: Princeton University, 2000.

Global political economy. Princeton: Princeton University, 2001.

GÓMEZ, J. M. O $2^{\underline{0}}$ Fórum Social Mundial de Porto Alegre e os desafios do movimento social global. Contexto Internacional, Rio de Janeiro, v. 24, n. 2, jul./dez. 2002.

GONÇALVES, R. Globalização e desnacionalização. São Paulo: Paz e Terra, 1999.

GUIMARÃES, S. P. Quinhentos anos de periferia. Porto Alegre: UFRGS; Rio de Janeiro: Contraponto, 1999.

HELD, D.; MCGREW, A. Prós e contras da globalização. Rio de Janeiro: Jorge Zahar, 2001.

HIRST, P.; THOMPSON, G. Globalização em questão. A economia internacional e as possibilidades de governabilidade. Petrópolis: Vozes, 1998.

HURRELL, A. O ressurgimento do regionalismo na política mundial. Contexto Internacional, Rio de Janeiro, v. 17, n. 1, p. 23-59, jan./jun. 1995.

IGLESIAS, R. M.; VEIGA, P. da M. Promoção de exportações via internacionalização das firmas de capital brasileiro. In: PINHEIRO, A. C.; MARKWALD, R.; PEREIRA, L. V. O desafio das exportações. Rio de Janeiro: BNDES, 2002. 
JAGUARIBE, Hélio. Evolução da política externa. In: ALBUQUERQUE, J. A. G. (Org.). Sessenta anos de política externa brasileira (1930-1990). Crescimento, modernização e política externa. v. 1. São Paulo: Cultura Editores Associados, 1996.

LAFER, Celso. A OMC e a regulamentação do comércio internacional: uma visão brasileira. Porto Alegre: Livraria do Advogado, 1998.

LAPLANE, M.; SARTI, F. Investimento direto estrangeiro e o impacto na balança comercial nos anos 90. Brasília: Ipea, 1999. (Texto para Discussão n. 629).

MORAN, T. H. Foreign direct investment and development. The new agenda for developing countries and economies of transition. Washington, DC: Institute for International Economics, 1998.

NONNENBERG, M. Determinantes dos investimentos externos e impactos das empresas multinacionais no Brasil — as décadas de 1970 e 1990. Rio de Janeiro: Ipea, 2003. (Texto para Discussão n. 969).

OHMAE, K. The bordeless world: power and strategy in the interlinked economy. New York: Free Press, 1990.

OLIVEIRA JR., M. M.; BORINI, F. M. Relevância estratégica das subsidiárias brasileiras para as corporações multinacionais. In: ENCONTRO ANUAL DA ANPAD, 23., Atibaia, 2003. Anais... Atibaia: Anpad, 2003.

PEREIRA, L. V. Estratégias de desenvolvimento regional: Mercosul, Nafta e Alca. In: BRIGAGÃO, C. Estratégias de negociações internacionais. Rio de Janeiro: Aeroplano, 2001.

PINHEIRO, A. C.; MARKWALD, R.; PEREIRA, L. V. O desafio das exportações. Rio de Janeiro: BNDES, 2002.

REBELO, A.; FERNANDES, L.; CARDIM, C. H. (Orgs.). Seminário política externa do Brasil para o século XXI. Brasília: Câmara dos Deputados, Coordenação de Publicações, 2003.

REZA, G. A. Ilusão de acesso: o modelo Alca. Contexto Internacional, Rio de Janeiro, v. 24, n. 2, jul./dez. 2002.

RICUPERO, R. O Brasil, a América Latina e os EUA desde 1930: 60 anos de uma relação triangular. In: ALBUQUERQUE, J. A. G. (Org.). Sessenta anos de política externa brasileira (19301990). Crescimento, modernização e política externa. v. 1. São Paulo: Cultura Editores Associados, 1996.

ROCHA, A. (Org.). A internacionalização das empresas brasileiras. Rio de Janeiro: Mauad, 2002.

RODRIGUES, S. (Org.). Competitividade, alianças estratégicas e gerência internacional. São Paulo: Atlas, 1999.

RUIGROK, W.; VAN TULDER, R. The logic of international restructuring. London: Routledge, 1995. 
SIFFERT, N. F.; SILVA, C. S. As grandes empresas nos anos 90: respostas estratégicas a um cenário de mudanças. In: GIAMBIAGI, F.; MOREIRA, M. M. (Orgs.). A economia brasileira nos anos 90. Rio de Janeiro: BNDES, 1999.

SANTOS, B. de S. Para uma concepção multicultural dos direitos humanos. Contexto Internacional, Rio de Janeiro, v. 23, n. 1, p. 7-34, jan./jun. 2001.

SANTOS, H. Grupos de interesse e redes de políticas públicas: uma análise da formulação de política industrial. Civitas, v. 2, n. 1, p. 193-210, 2002.

SKLAIR, L. Sociologia do sistema global. Petrópolis: Vozes, 1995.

—. The transnational capitalist class. Oxford: Blackwell, 2001.

STERNBERG, R. Innovation networks and regional development-evidence from the European Regional Innovation Survey. European Planning Studies, v. 8, n. 4, p. 389-409, 2000.

STOPFORD, J.; STRANGE, S. Rival States and rival firms: competition for world market shares. Cambridge: Cambridge University Press, 1991.

STRANGE, S. States and markets. 2. ed. London: Pinter, 1994.

- The retreat of the State. Cambridge: Cambridge University Press, 1996.

THOMPSON, G. Economic globalization? In: HELD, D. (Ed.). A globalizing world? Culture, economics, politics. London, Routledge; New York; The Open University, 2000.

UNCTAD - UNITED NATIONS CONFERENCE ON TRADE AND DEVELOPMENT. FDI determinants and TNC strategies: the case of Brazil. New York; Geneva: United Nations, 2000.

World investment report 2002: transnational corporations and export competitiveness. New York; Geneva: United Nations, 2002.

World investment report 2003: FDI policies for development: national and international perspectives. New York; Geneva: United Nations, 2003.

Política de investimentos no Brasil. Panorama Geral e Recomendações. Brasília: Seminário Unctad/Pnud, 2004.

VIOLA, E.; OLIVIERI, A. Globalização, sustentabilidade e governabilidade democrática no Brasil. In: TRINDADE, A. A. C.; CASTRO, M. F. (Orgs.). A sociedade democrática no fim do século. Brasília: Paralelo 15, 1997.

WILSON, R. Understanding local governance: an international perspective. Revista de Administração de Empresas, São Paulo, v. 40, n. 2, p. 51-63, abr./jun. 2000.

WORLD BANK. Governance and development. Washington, DC: The World Bank, 1992. 
Development in practice. Governance. The World Bank’s experience. Washington, DC: The World Bank, 1994.

RAP Rio de Janeiro 40(3):335-56, Maio/Jun. 2006 